\title{
Morphometric Analysis of Infraorbital Foramen in the Telangana Population
}

\author{
Masooma Begum 1 , B H Shiny Vinila ${ }^{2}$ \\ ${ }^{1}$ Assistant professor, Department of Anatomy, Mahaveer Institute of Medical Sciences, Vikarabad, Telangana, ${ }^{2}$ Senior Lecturer, Department of Anatomy, \\ Panineeya Institute of Dental Sciences, Hyderabad, Telangana.
}

\section{Abstract}

Introduction: The infraorbital foramen gives passage to the infraorbital nerve and vessels. The infraorbital nerve needs to be blocked to anaesthetise lower eyelid, lateral nose, upper lip, upper teeth and gingivae for various dental treatments or maxillofacial surgical procedures. The present study was undertaken to determine the size and location of the infraorbital foramen in Telanagana population. Subjects and Methods: The study was conducted on 52 skulls. The size was determined by taking maximum vertical and maximum transverse diameters. The location of the infraorbital foramen was determined by measuring the distance between the centre of the foramen and infraorbital margin, the distance from the centre of the foramen to piriform aperture, and the distance from the centre of the foramen to anterior nasal spine. Results: The mean vertical and transverse diameter of the infraorbital foramen was $3.57 \mathrm{~mm}$ and $2.88 \mathrm{~mm}$ on the right side and $3.18 \mathrm{~mm}$ and $2.98 \mathrm{~mm}$ on the left side respectively. The mean distance from the centre of the infraorbital foramen to infraorbital margin, anterior nasal spine and piriform aperture was $7.31 \mathrm{~mm}, 32.46 \mathrm{~mm}$ and $16.57 \mathrm{~mm}$ on the right side and $7.27 \mathrm{~mm}, 31.70 \mathrm{~mm}$ and $16.13 \mathrm{~mm}$ on the left side respectively. Conclusion: Knowledge about the exact size and location of the infraorbital foramen will be useful for the dental and maxillofacial surgeons to blocking the infraorbital nerve and also while performing various therapeutic procedures in this region.

Keywords: Infraorbital nerve block, infraorbital foramen, piriform aperture, anterior nasal spine, infraorbital margin.

Corresponding Author: Dr. Masooma Begum, Assistant Professor, Department of Anatomy, Mahaveer Institute of Medical Sciences, Shivareddypet, Vikarabad, Telangana. 501102.

Received: December 2019

Accepted: December 2019

\section{Introduction}

Infraorbital foramen is situated on the anterior surface of the maxilla below the infraorbital margin which gives passage to infraorbital nerve and vessels. ${ }^{[1]}$ Infraorbital nerve is a continuation of maxillary nerve which is purely sensory in function. The infraorbital nerve divides into 3 terminal branches palpebral, nasal, and labial branches after coming out from the foramen. The infraorbital nerve innervates the lower eye lid and conjunctiva, external surface of nose including ala of the nose, the upper lip, upper incisors, canine, premolars, and mesiobuccal root of the first molar on the ipsilateral side of the face. ${ }^{[2]}$

The exact location of the infraorbital foramen is very important as it is useful in the acupuncture to treat trigeminal neuralgia, to minimise the risk of orbital surgiries and zygoma fractures. ${ }^{[3-5]}$ The infraorbital plexus region is considered as the risk zone during the plastic surgeries. ${ }^{[6]}$ The morphometric analysis of the infraorbital foramen is essential to get success in the regional anesthesia by blocking the infraorbital nerve. ${ }^{[7,8]}$ The Infraorbital nerve is blocked through infraorbital foramen and infraorbital canal to anesthetize the lower eyelid, lateral part of external nose, upper lip, maxillary teeth and related gingivae. The regional anesthesia of infraorbital nerve is essential for the diagnostic, therapeutic, surgical procedures in the maxillofacial region. ${ }^{[9]}$ The therapeutic infraorbital nerve blocks are used in severe trigeminal neuralgia where the condition is nonresponsive to the medication. ${ }^{[10]}$ The infraorbital nerve block is not preferred by the dentists because of the increase risk of damage to the eye. ${ }^{[1]}$

The proper knowledge on the size and location of the infraorbital foramen is very much essential for the dentists, maxillofacial surgeons and plastic surgeons. The present study was focused on the determination of the size, location of the infraorbital foramen in Telangana population.

\section{Subjects and Methods}

The present study was a cross sectional study consisting of 52 adult dry human skulls. All these skulls were collected from the department of Anatomy, Mahaveer Institute of Medical Sciences, Vikarabad. Damaged skulls especially in the infraorbital region were excluded from the study. The size of the infraorbital foramen was determined by measuring the vertical and the horizontal diameters of the infraorbital foramen [Figure $1 \& 2$ ]. The location of the 


\section{Begum \& Vinila; Marphametric Analysis of Infraarbital Faramen}

infraorbital foramen was determined by measuring the distance from the centre of the infraorbital foramen to infraorbital margin [Figure 3], distance from the centre of the infraorbital foramen to anterior nasal spine [Figure 4], distance from the centre of the infraorbital foramen to piriform aperture [Figure 5]. The measurements were taken by the digital vernier calipers.

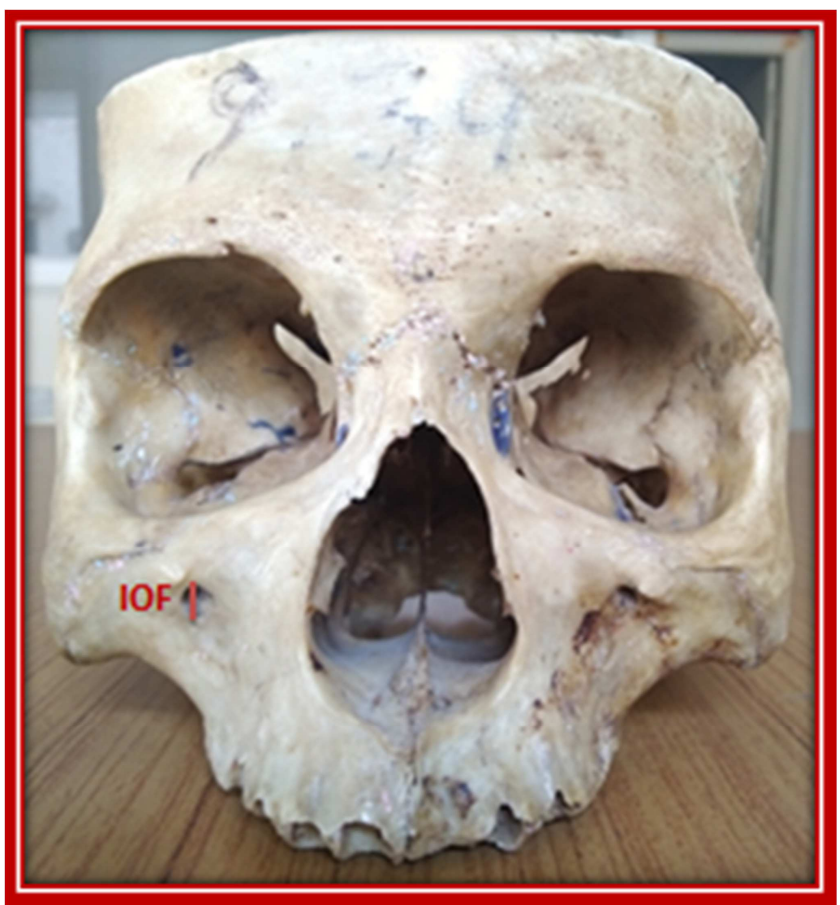

Figure 1: Measurement of the vertical diameter of the infraorbital foramen (IOF).

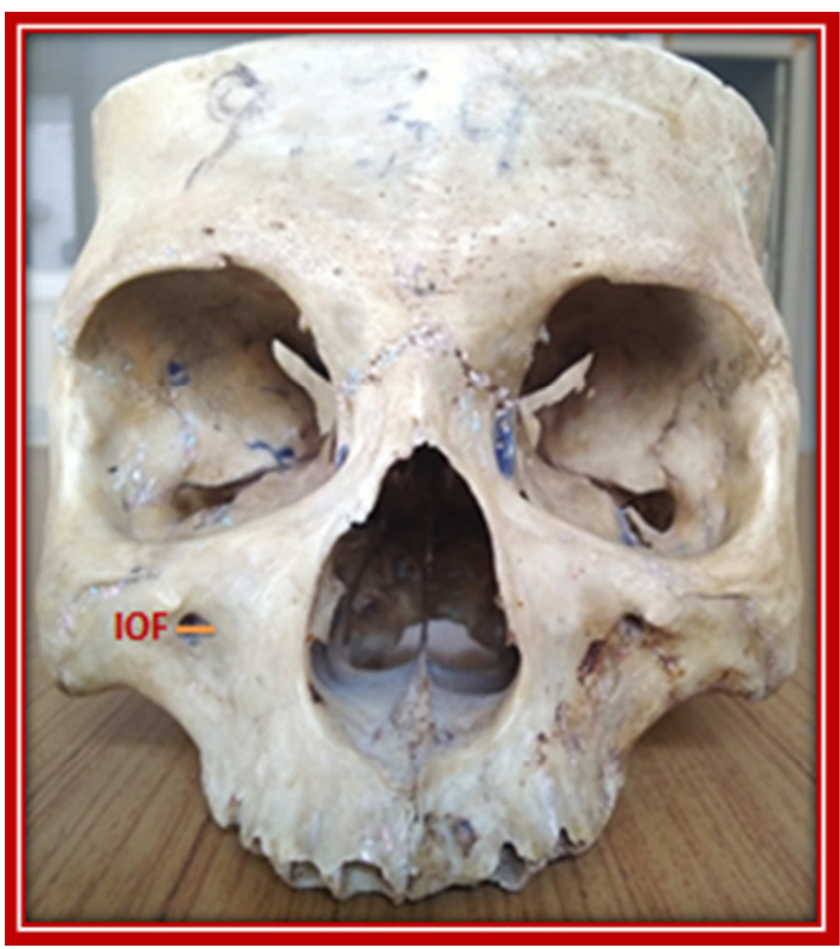

Figure 2: Measurement of the Horizontal diameter of the infraorbital foramen (IOF)

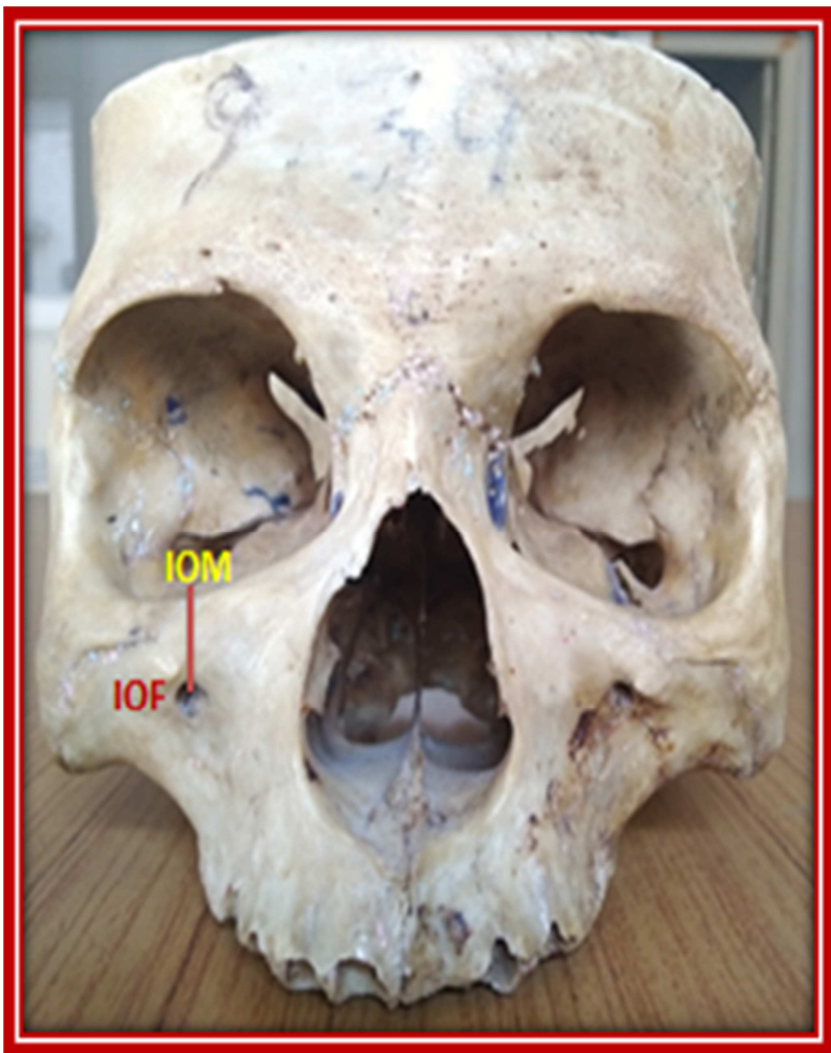

Figure 3: Distance between inferior orbital margin (IOM) and the centre point of infraorbital foramen (IOF)

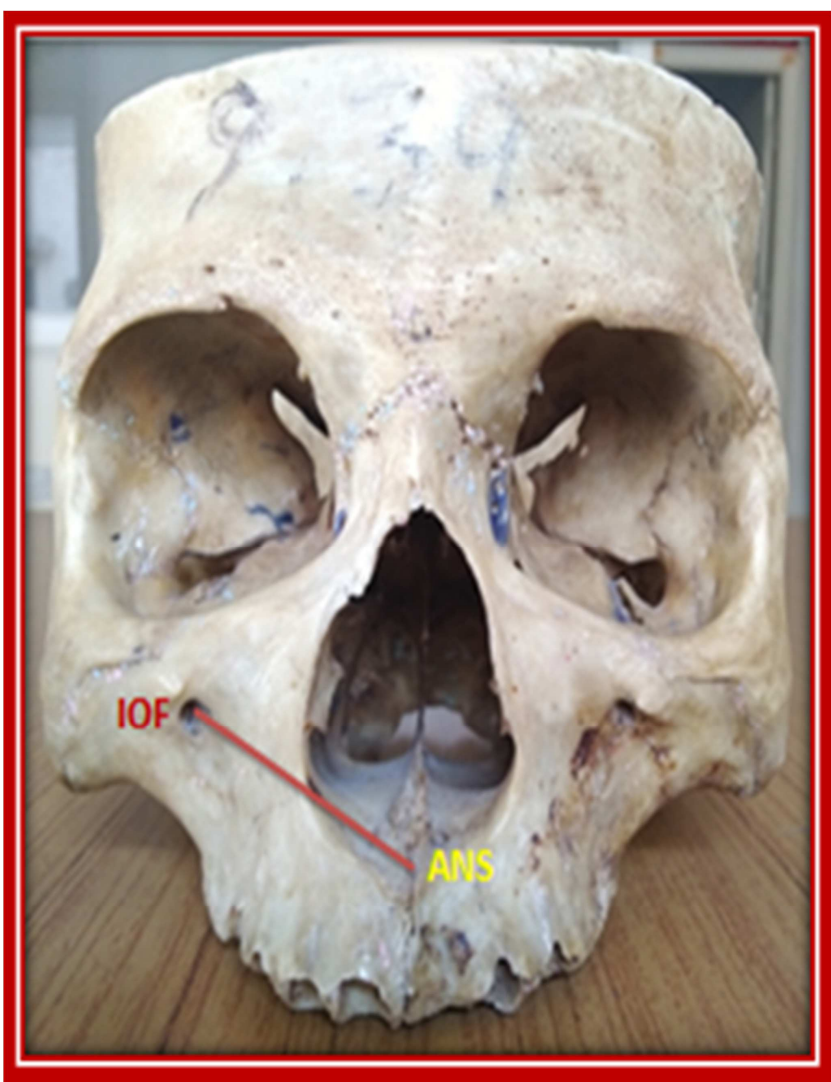

Figure 4: Distance between the anterior nasal spine (ANS) and the centre point of infraorbital foramen (IOF). 


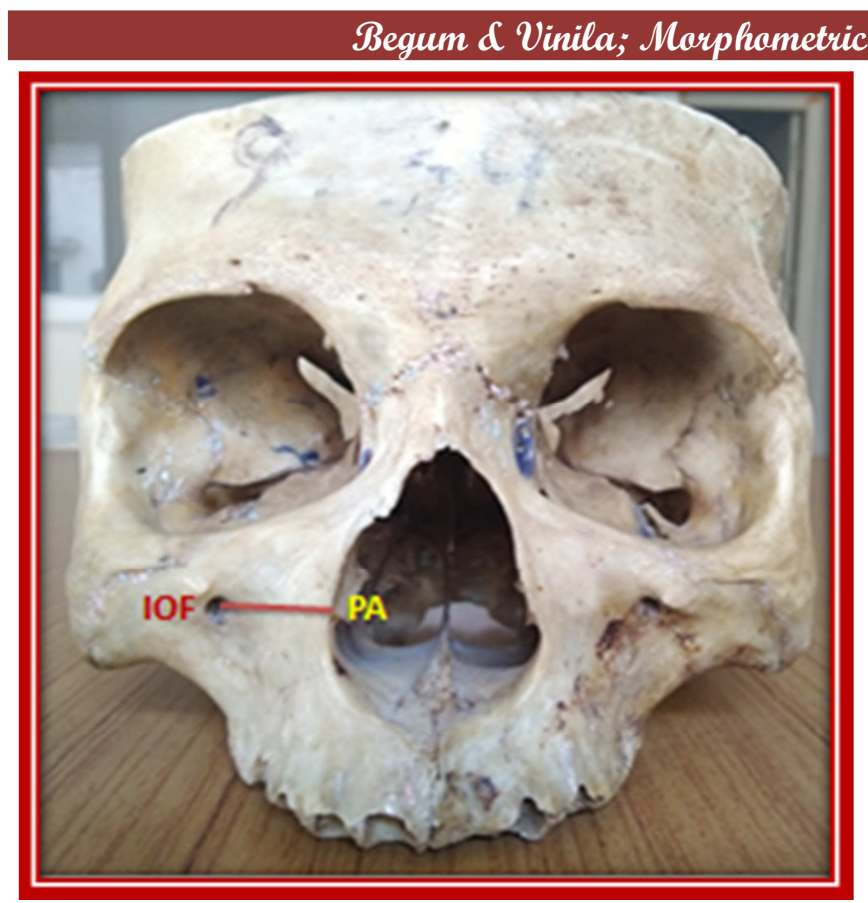

nalysis of Infraarlital Faramen

Figure 5: Distance between the piriform aperture (PA) of the nose and the infraorbital foramen (IOF).

\section{Results}

In the present study the size of the infraorbital foramen was determined by taking maximum vertical diameter and maximum transverse diameter. The average vertical diameter of the infraorbital foramen was $3.57 \pm 0.85 \mathrm{~mm}$ on the right side and $3.18 \pm 0.83 \mathrm{~mm}$ on the left side. The average transverse diameter of the infraorbital foramen was $2.88 \pm 0.62 \mathrm{~mm}$ on the right side and $2.98 \pm 0.59 \mathrm{~mm}$ on the left side. The average distance from the centre of the infraorbital foramen to infraorbital margin was $7.31 \pm 1.54$ $\mathrm{mm}$ on the right side and $7.27 \pm 1.43 \mathrm{~mm}$ on the left side. The average distance from the centre of the infraorbital foramen to anterior nasal spine was $32.46 \pm 2.55 \mathrm{~mm}$ on the right side and $31.70 \pm 2.36 \mathrm{~mm}$ on the left side. The average distance from the centre of the infra-orbital foramen to piriform aperture was $16.57 \pm 1.90 \mathrm{~mm}$ on the right side and $16.13 \pm 1.71 \mathrm{~mm}$ on the left side. There was no significant difference between the right and left sides in all the parameters [Figure 6].

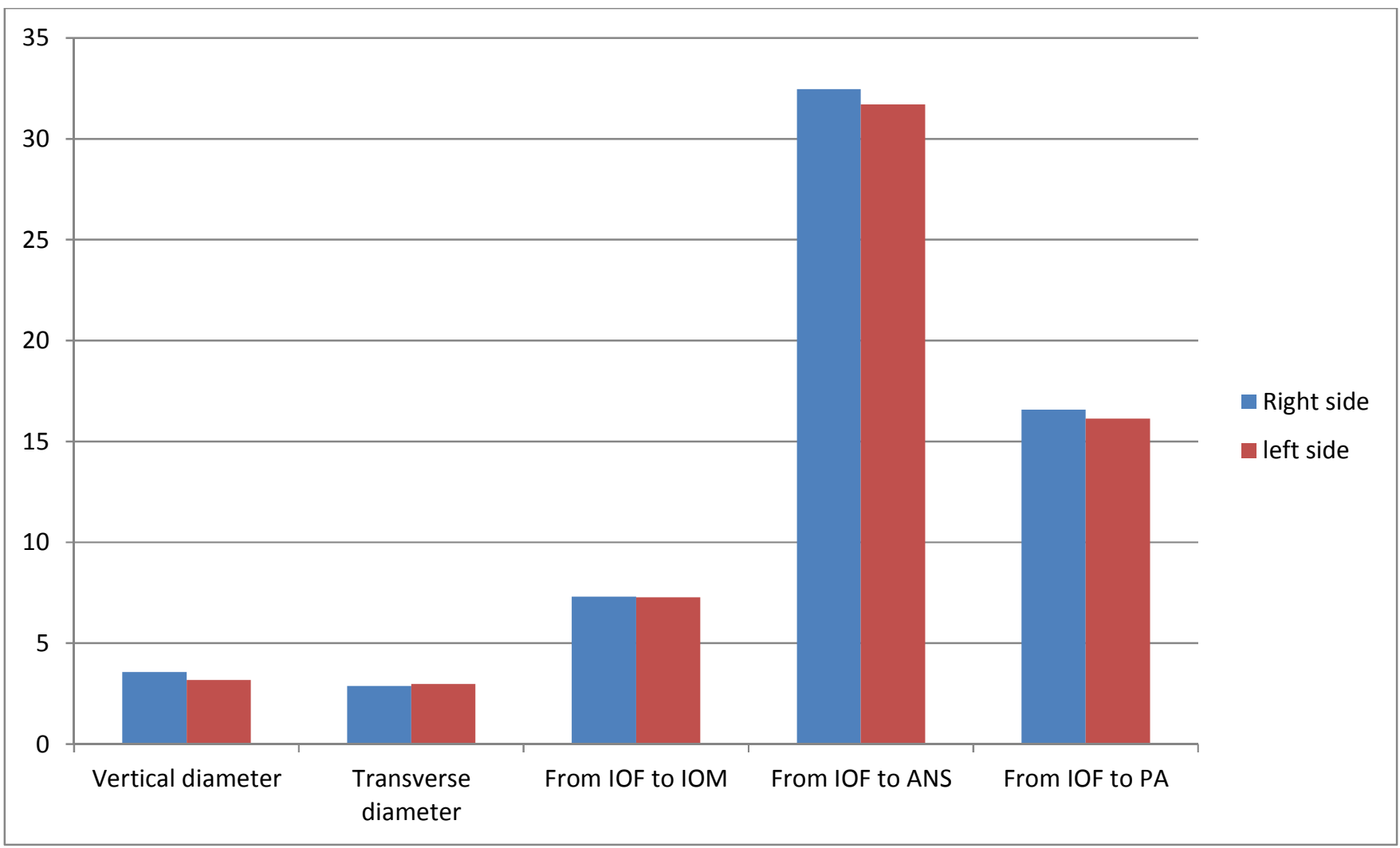

Figure 6: The bar diagram showing the difference between the right and the left sides of all the parameters of infra-orbital region.

\section{Discussion}

The infraorbital nerve is considered as a prime candidate nerve for regional nerve block in local anaesthesia as it provides sensory innervation to the considerably large area extending from the lower eyelid to the upper lip. The localization of the infraorbital foramen is very much essential to the infraorbital nerve and vessels emerge out through it. Identification of the location of the infraorbital nerve is very important during the surgeries of maxillofacial region, maxillary air sinus and also while administering the infraorbital nerve block. Injury to the infraorbital nerve may cause significant morbidity such as the numbness or sensory loss of the infra orbital region including the lateral wall of nose and upper lip. ${ }^{[12,13]}$ 
The size of the infraorbital foramen was determined by measuring the maximum vertical and horizontal diameters. The vertical diameter in the present study was $3.57 \pm 0.85$ $\mathrm{mm}$ on its right side and $3.18 \pm 0.83 \mathrm{~mm}$ on its left side. The maximum horizontal diameter in the present study was 2.88 $\pm 0.62 \mathrm{~mm}$ on the right side and $2.98 \pm 0.59 \mathrm{~mm}$ on the left side which were similar to the results of the other studies by Deepthi Nanayakkara el al., Rajani Singh et al., Supriya Garapati et al., and Boopathi et al., but little smaller that the study by Kopal Saini et al., where they reported the mean vertical diameter as $4.3 \pm 0.95 \mathrm{~mm}$ and the mean horizontal or transverse diameter as $3.60 \pm 0.84 \mathrm{~mm} .^{[11,14-17]}$

In the present study the distance from the infra orbital foramen to infra orbital margin was $7.31 \pm 1.54 \mathrm{~mm}$ on the right side and $7.27 \pm 1.43 \mathrm{~mm}$ on the left side which were similar with the results of K K Gour et al., Hussain Sahib et al., and Kazkaysi $\mathrm{M}$ et al., and they reported it as $7.39 \pm 1.63$ $\mathrm{mm}, 7.13 \pm 1.78 \mathrm{~mm}$ and $7.19 \pm 1.39 \mathrm{~mm}$ respectively. ${ }^{[2,10,18]}$ Ilayperma et al., reported the distance between the infraorbital foramen and the infraorbital margin as $10.56 \pm$ $1.7 \mathrm{~mm}$ in males and $9.02 \pm 1.58 \mathrm{~mm}$ in females in Srilanka population and Apinhasmit et al., reported it as $9.53 \pm 2.23$ $\mathrm{mm}$ in males and $8.71 \pm 1.51 \mathrm{~mm}$ in females in Thailand population. ${ }^{[19,20]}$ These values were much higher than the results of the present study.

The mean distance between the infraorbital foramen to piriform aperture was $16.57 \pm 1.90 \mathrm{~mm}$ on the right side and $16.13 \pm 1.71 \mathrm{~mm}$ on the left side which were similar with other studies by Rajani singh et al., Lokanayaki et al., and Tilak Raj et al., but little higher that the studies by M G Elias, Oliveria $\mathrm{J}$ et al., and little lower than the values reported by Kopal Saini et al., and Supriya Garapati et al., as described in the [Table 1]. ${ }^{[15-17,21-24]}$

Table 1: Comparison of mean distances from the infraorbital foramen to piriform aperture reported in previous studies

\begin{tabular}{|l|l|l|}
\hline \multirow{2}{*}{ Studies/ Author } & $\begin{array}{l}\text { Distance between the IOF to } \\
\text { Piriform } \\
\text { millimeters) } \\
\text { aperture }\end{array}$ \\
\cline { 2 - 3 } & Right side & Left side \\
\hline Rajani singh et al., ${ }^{[15]}$ & 15.31 & 15.8 \\
\hline Lokanayaki et al., ${ }^{[2]]}$ & 16.58 & \\
\hline Tilak Raj et al., ${ }^{[2]}$ & $15.79 \pm 1.76$ & $16.14 \pm 1.72$ \\
\hline M G Elias et al., ${ }^{[22]}$ & $13.28 \pm 2.17$ & $13.31 \pm 2.19$ \\
\hline Oliveria J et al., ${ }^{[2]]}$ & $13.67 \pm 2.17$ & $14.26 \pm 1.83$ \\
\hline Kopal Saini et al., ${ }^{[17]}$ & $17.4 \pm 2.43$ \\
\hline Supriya Garapati et al., ${ }^{[16]}$ & $18.36 \pm 3.2$ & $17.8 \pm 3.42$ \\
\hline
\end{tabular}

The mean distance between the infraorbial foramen and the anterior nasal spine in the present study was $32.46 \pm$ $2.55 \mathrm{~mm}$ on the right side and $31.70 \pm 2.36 \mathrm{~mm}$ on the left side. These values were smaller than the other studies by Ekambaram et al., who reported it as $36.3 \mathrm{~mm}$ on the right side and $36 \mathrm{~mm}$ on the left side in males and $34.31 \mathrm{~mm}$ on the right side and 33.01 on the left side in females. Agthong et al., reported it as $34.8 \mathrm{~mm}$ and $35 \mathrm{~mm}$ on the right and the left sides respectively in males and $32.8 \mathrm{~mm}$ and $33.1 \mathrm{~mm}$ on the right and the left sides respectively in females, which were nearer to the results of the present study. ${ }^{[25,26]}$

\section{Conclusion}

The results of the present study provides the knowledge about the exact size and location of the infraorbital foramen which will be useful for the dental and maxillofacial surgeons, plastic surgeons who deal with the infraorbital region to blocking the infraorbital nerve and also while performing various surgical or therapeutic procedures in this region.

\section{References}

1. Aziz SR, Marchena JM, Puran A. Anatomic characteristics of the infraorbital foramen: A cadaver study. J Oral Maxillofac Surg 2000; 58:992-6

2. Gaur K K, Nair S, Trivedi G N, Guptha S D. Anthropometric measurements of infraorbital foramen in dried human skulls. Int J Biol Med Res 2012; 3(3): 2003- 2006.

3. Esper R S, Yara J, Yamamura Y, Cricenti S V. Relações anatômicas do ponto de acupuntura E-2 (Sibai) localizado no forame infraorbital. Rev Paul Acupunt. 1998; 4:19-21.

4. Karakaş P, Bozkir M G, Oguz O. Morphometric measurements from various reference points in the orbit of male Caucasians. Surg Radiol Anat. 2003; 24: 358-362.

5. Du Tolt DF, Nortjé C. The maxillae: integrated and applied anatomy relevant to dentistry. SADJ. 2003; 58:325-330.

6. Hwang K, Han JY, Battuvshin D, Kim DJ, Chung IH. Communication of infraorbital nerve and facial nerve: anatomic and histologic study. J Craniofac Surg. 2004; 15: 88-91.

7. Chung MS, Kim HJ, Kang HS, Chung IH. Locational relationship of the supraorbital notch or foramen and infraorbital and mental foramina in Koreans. Acta Anat (Basel) 1995; 154: 162-166.

8. Radwan IA, Saito S, Goto F. High-concentration tetracaine for the management of trigeminal neuralgia: quantitative assessment of sensory function after peripheral nerve block. Clin J Pain. 2001; 17: 323-326.

9. Gruber W. A hook shaped canal overand above the infraorbital foramen. Arc Pathol Anat Physiol Klin Med 1878; 72: 494-6.

10. Kazkayasi M, Ergin A, Ersoy M, Bengi O, Tekdemir I, Elhan A. Certain anatomic relations and the precise morphometry of the infraorbital foramen canal and groove: An anatomical and cephalometric study. Laryngoscope 2001; 111: 609-14.

11. Boopathi S, Chakravarthy MS, Dhalapathy S, Anupa S. Anthropometric analysis of the infraorbital foramen in a South Indian population. Singapore Med J, 2010; 51(9): 730-735.

12. S. Standring, Gray's Anatomy: Anatomical Basis of Clinical Practice, Churchill Livingstone Elsevier, London, UK, 40th edition, 2008.

13. R. K. Chandra and D. W. Kennedy, "Surgical implications of an unusual anomaly of the infraorbital nerve," Ear, Nose and Throat Journal. 2004; 83 (11): 766-767.

14. Deepthi Nanayakkara, Roshan Peiris, Navini Mannapperuma, and Amal Vadysinghe. Morphometric Analysis of the Infraorbital Foramen: The Clinical Relevance. Anatomy research international. 2016; Article Id: 7917343; 8 pages.

15. http://dx.doi.org/10.1155/2016/7917343

16. Rajani Singh. Morphometric analysis of infraorbital foramen in Indian dry skulls, Anat Cell Biol. 2011; 44: 79-83.

17. Supriya Garapati, N. Himabindu, V. Padmaja, Ch. Santhi, P. Sharmila Bhanu. Morphology and morphometric study of inferior ortibal foramen. Int J Anat Res 2016; 4(2): 2304-2307. DOI: 10.16965/ijar.2016.201

18. Kopal Saini. Descriptive and Topographic Anatomy of Infraorbital Foramen And Its Clinical Implication In Nerve Block International Journal of Anatomy and Research, Int J Anat Res. 2014; 2(4): 73034.

19. Shaik HS, Shepur MP, Desai SD, Thomas ST, Maavishettar GF, Haseena S. Morphometric analysis of Infra orbital foramen position in south Indian skulls. Indian J Innovations Dev 2012; http://iseeadyar.org /ijid.html

20. I. Ilayperuma, G. Nanayakkara, and N. Palahepitiya, "Morphometric analysis of the infraorbital foramen in adult Sri Lankan skulls," International Journal of Morphology. 2010; 28 (3): 


\section{Begum d Vinila; Marphametric Analysis of Infrawatlital Faramen}

777-782.

21. W. Apinhasmit, S. Chompoopong, D. Methathrathip, R. Sansuk, and W. Phetphunphiphat, "Supraorbital notch/foramen, infraorbital foramen and mental foramen in Thais: anthropometric measurements and surgical relevance," Journal of the Medical Association of Thailand. 2006; 89 (5): 675-682.

22. Lokanayaki V, Anatomic Variations Of Infraorbital Foramen. Cib Tech journal of surgery. 2013; 2(2): 306.

23. Elias MG, silva RB, PimenteIML, CardosoVTS, Rivello T, Babinski MA. Morphometric analysis of the infraorbital foramen and accessory foraminas in Brazilian skulls, int. j. Morphol. 2004; 22(4): 273-8.

24. Oliveira j, de EM, Moreira RT, Neto BL, Silva CMF da,Lima FJC. A morphological and biometric study of the infraorbital foramen in adult skulls. Int. j. Morphol 2012; 30(3): 986-92.

25. Tilak Raj, Anshu Mishra, Parmatma Mishra. Morphometric analysis of infraorbital foramen in north Indian skulls. Indian journal of Basic and Applied medical research. 2014; 4(1): 185192.

26. S. Agthong, T. Huanmanop, and V. Chentanez, "Anatomical variations of the supraorbital, infraorbital, and mental foramina related to gender and side," Journal of Oral and Maxillofacial Surgery. 2005; 63 (6): 800-804.

27. G. Ekambaram, R. Shaik, D. Salmani, and G. Ekambaram, "A gender wise study on the morphometry of infraorbital foramen and its laterally in dry adult skulls of South Indian population," International Journal of Medical Science and Public Health. 2014; 3 (5): 546.

Copyright: () the author(s), publisher. Academia Anatomica International is an Official Publication of "Society for Health Care \& Research Development". It is an open-access article distributed under the terms of the Creative Commons Attribution Non-Commercial License, which permits unrestricted non-commercial use, distribution, and reproduction in any medium, provided the original work is properly cited.

How to cite this article: Begum M, Vinila BHS. Morphometric Analysis of Infraorbital Foramen in the Telangana Population. Acad. Anat. Int. 2019;5(2):90-94.

DOI: dx.doi.org/10.21276/aanat.2019.5.2.24

Source of Support: Nil, Conflict of Interest: None declared. 